\title{
Conjugates of Phthalocyanines With Oligonucleotides as Reagents for Sensitized or Catalytic DNA Modification
}

\author{
Alexander A. Chernonosov, ${ }^{1,2,3}$ Vladimir V. Koval, ${ }^{1,2}$ Dmitrii G. Knorre, ${ }^{1,2}$ Alexander A. Chernenko, ${ }^{4}$ \\ Valentina M. Derkacheva, ${ }^{5}$ Eugenii A. Lukyanets, ${ }^{5}$ and Olga S. Fedorova ${ }^{1,2}$ \\ ${ }^{1}$ Institute of Chemical Biology and Fundamental Medicine, Siberian Division of the Russian Academy of Sciences, \\ Lavrentyev Avenue 8, Novosibirsk 630090, Russia \\ ${ }^{2}$ Novosibirsk State University, Pyrogova Street 2, Novosibirsk 630090, Russia \\ ${ }^{3}$ Institute of Human Ecology, Sovetskii Avenue 18, Kemerovo 650099, Russia \\ ${ }^{4}$ Institute of Semiconductor Physics, Siberian Division of the Russian Academy of Sciences, Lavrentyev Avenue 13, \\ Novosibirsk 630090, Russia \\ ${ }^{5}$ Organic Intermediates and Dyes Institute, B. Sadovaya 1/4, Moscow 103787, Russia
}

Received 20 August 2004; Revised 1 December 2004; Accepted 3 December 2004

Several conjugates of metallophthalocyanines with deoxyribooligonucleotides were synthesized to investigate sequence-specific modification of DNA by them. Oligonucleotide parts of these conjugates were responsible for the recognition of selected complementary sequences on the DNA target. Metallophthalocyanines were able to induce the DNA modification: phthalocyanines of $\mathrm{Zn}(\mathrm{II})$ and $\mathrm{Al}(\mathrm{III})$ were active as photosensitizers in the generation of singlet oxygen ${ }^{1} \mathrm{O}_{2}$, while phthalocyanine of $\mathrm{Co}$ (II) promoted DNA oxidation by molecular oxygen through the catalysis of formation of reactive oxygen species $\left({ }^{\cdot} \mathrm{O}_{2}{ }^{-}, \mathrm{H}_{2} \mathrm{O}_{2}, \mathrm{OH}\right)$. Irradiation of the reaction mixture containing either $\mathrm{Zn}$ (II)- or $\mathrm{Al}$ (III)-tetracarboxyphthalocyanine conjugates of oligonucleotide pd(TCTTCCCA) with light of $>340 \mathrm{~nm}$ wavelength ( $\mathrm{Hg}$ lamp or $\mathrm{He} / \mathrm{Ne}$ laser) resulted in the modification of the 22-nucleotide target d(TGAATGGGAAGAGGGTCAGGTT). A conjugate of Co(II)-tetracarboxyphthalocyanine with the oligonucleotide was found to modify the DNA target in the presence of $\mathrm{O}_{2}$ and 2-mercaptoethanol or in the presence of $\mathrm{H}_{2} \mathrm{O}_{2}$. Under both sensitized and catalyzed conditions, the nucleotides $\mathrm{G}^{13}-\mathrm{G}^{15}$ were mainly modified, providing evidence that the reaction proceeded in the double-stranded oligonucleotide. These results suggest the possible use of phthalocyanine-oligonucleotide conjugates as novel artificial regulators of gene expression and therapeutic agents for treatment of cancer.

Copyright (c) 2006 Alexander A. Chernonosov et al. This is an open access article distributed under the Creative Commons Attribution License, which permits unrestricted use, distribution, and reproduction in any medium, provided the original work is properly cited.

\section{INTRODUCTION}

Design of sequence-specific DNA- or RNA-modifying reagents requires conjugation of recognition and reactive groups in a single molecule. Oligonucleotides, which are fragments of single-stranded RNA or DNA, possess an inherent ability to anneal to the respective complementary sequences of the nucleic acids inside cells. This specific interaction results in the formation of double-stranded complexes and provides a recognition mechanism necessary for copying and correcting genetic material. Because of their unique targeting ability, oligonucleotides are of particular interest in chemotherapy. They can serve as specific tags for nucleicacid-damaging drugs. Inherently, nonspecific chemical compounds can be converted into accurate weapons when coupled to oligonucleotides. The reactive derivatives of oligonu- cleotides represent a wide class of specific reagents proposed for regulating gene expression (for a review, see [1]). This approach, relying on sequence-specific targeting of reactive compounds, was initially called "complementary addressed modification of nucleic acids" [2]. In its initial implementation, it was suitable for the modification of single stranded polynucleotide chains. Later, the approach was expanded to include nonreactive oligonucleotides and their synthetic analogs, forming the basis of the "antisense" technology (reviewed in [3]). It was also shown that the same method may be used for certain double-stranded nucleic acids capable of forming triple-stranded complexes ("antigene" approach) [4-6]. Presently, the methodology is considered universally applicable to suppress the development of viral infections as well as tumors induced by mutations in protooncogenes responsible for malignant cell transformation. 


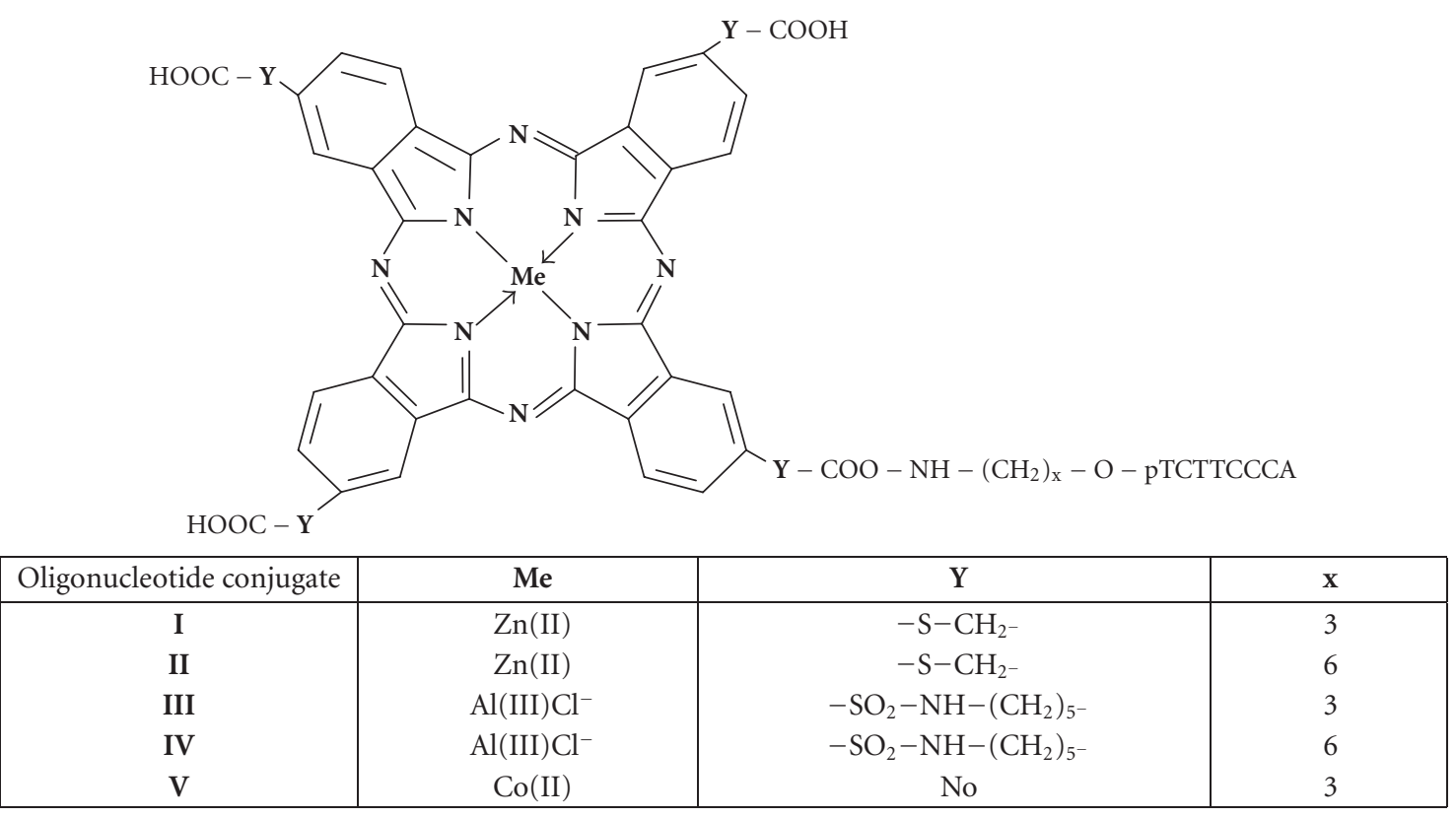

FIGURE 1: Structures of the phthalocyanine conjugates.

(5') TGAAT $\stackrel{5}{ }{ }^{\prime}$ GGGAAGAGGGTCAGGTT

(3') $\quad \dot{\mathrm{A}} \dot{\mathrm{C}} \dot{\mathrm{C}} \dot{\mathrm{C}} \mathrm{T} \dot{\mathrm{T}} \dot{\mathrm{C}} \mathrm{T} \mathrm{p}-\mathrm{Pt} \mathrm{c}$

FIgURE 2: Sequence of the oligonucleotide duplex used for the complementary-addressed DNA modification. Ptc, tetra-4-carboxyphtalocyanine of $\mathrm{Co}(\mathrm{II}), \mathrm{Al}(\mathrm{III})$, or $\mathrm{Zn}(\mathrm{II})$, attached to the $5^{\prime}$ terminal phosphate of the addressing oligonucleotide via aminopropanol or aminohexanol linkers.

Various chemical groups were studied as reactive moieties in oligonucleotide conjugates [1]. Phthalocyanines have a number of chemical properties making them effective reagents for nucleic acid modification. They can both act as good photosensitizers, promoting singlet molecular oxygen formation, and effectively catalyze oxidation of organic molecules by molecular oxygen in dark. The presence of bridging nitrogen atoms in these compounds results in efficient absorption at $600-700 \mathrm{~nm}$, making them sensitive to the light of this wavelength, which can penetrate deep into living tissues [7]. This property of phthalocyanines is used in photodynamic therapy (PDT) of cancer [8]. Singlet molecular oxygen ${ }^{1} \mathrm{O}_{2}$ is active towards different cell components (nucleic acids, proteins, lipids) [9].

On the other hand, phthalocyanine complexes with some paramagnetic metal ions are able to catalyze formation of reactive oxygen species (ROS) such as superoxide radical, hydrogen peroxide, and hydroxyl radicals via reductive-oxidative mechanism. These species damage different biomolecules [10]. The complex of phthalocyanine with $\mathrm{Co}(\mathrm{II})$ is known to be one of the most effective catalysts in the oxidation of different substrates with molecular oxygen and hydrogen peroxide [11].
The main goal of the present work is to address the possibility of the modification of DNA by phthalocyanines of $\mathrm{Al}(\mathrm{III})$ and $\mathrm{Zn}(\mathrm{II})$ as sensitizers and $\mathrm{Co}(\mathrm{II})$-phthalocyanine as a catalytic group conjugated to oligonucleotides. The structures of metallophthalocyanine conjugates are presented in Figure 1.

\section{EXPERIMENTAL METHODS}

\section{Chemicals and reagents}

Acrylamide, N,N'-methylene-bisacrylamide, urea, acetonitrile, DMF (Fluka, Switzerland), 1,3-diaminopropane (Merck, Germany), Tris-HCl, and 2-mercaptoethanol (Sigma, USA) were used. All buffer solutions were prepared with double-distilled water using ultrapure reagents. $E$ coli 8-oxoguanine-DNA glycosylase was a courtesy of $\mathrm{Dr}$ A A Ishchenko, (ICBFM, Novosibirsk, Russia). All phthalocyanines investigated contained four carboxyl groups, which were used for conjugation with amino groups of the linkers attached to the $5^{\prime}$-terminal phosphate of the octanucleotide (8-nt).

\section{Oligonucleotides and conjugates}

The 8-nt and 22-nt deoxyribonucleotides $5^{\prime}$-pdTCTTCCCA$3^{\prime}$ and $5^{\prime}$-dTGAATGGGAAGAGGGTCAGGTT-3' (Figure 2) were synthesized on an ASM-700 automated synthesizer (BIOSSET Ltd., Novosibirsk, Russia) from phosphoramidites purchased from Glen Research (Sterling, Va, USA) according to the manufacturer's protocol. The oligonucleotides were deprotected with ammonium hydroxide and purified by ion exchange HPLC on a Nucleosil 100-10 $\mathrm{N}\left(\mathrm{CH}_{3}\right)_{2}$ column followed by reverse-phase HPLC on a Nucleosil 100-7 $\mathrm{C}_{18}$ 
column (both $4.6 \times 250 \mathrm{~mm}$, purchased from MachereyNagel, Düren, Germany). The purity of oligonucleotides exceeded $98 \%$, as estimated by electrophoresis in $20 \%$ denaturing polyacrylamide gel after staining with Stains-All dye (Sigma-Aldrich, St Louis, Mo, USA). Concentrations of oligonucleotides were determined from their absorbance at $260 \mathrm{~nm}$ [12]. The 22-nt oligonucleotide was used as a DNA target; the 8-nt oligonucleotide was used for the synthesis of conjugates with phthalocyanines.

The oligonucleotide conjugates with phthalocyanine complexes of $\mathrm{Al}(\mathrm{III}), \mathrm{Zn}(\mathrm{II})$, and $\mathrm{Co}(\mathrm{II})$ were synthesized using a previously reported solid-phase method [13] with a $30-40 \%$ yield. The conjugates were isolated from the reaction mixture and purified by HPLC in an acetonitrile/water gradient. Reverse-phase HPLC profiles with different retention times for the free oligonucleotide and for the phthalocyanine-oligonucleotide conjugates provided a strong proof that the phthalocyanine moiety was covalently attached to the oligonucleotide [13].

\section{5'-terminal phosphorylation}

The 22-nt oligonucleotide was labeled with ${ }^{32} \mathrm{P}$ at the $5^{\prime}$ end in a $30 \mu \mathrm{L}$ reaction mixture containing $30 \mathrm{pmol}$ of the oligonucleotide, $30 \mathrm{pmol}$ of $\left[\gamma-{ }^{32} \mathrm{P}\right]$ ATP (specific activity $\left.3.3 \times 10^{-3} \mathrm{mCi} / \mathrm{pmol}\right)$, and $10-20$ units of T4 polynucleotide kinase (Sibenzyme, Russia) in a buffer containing $0.05 \mathrm{M} \mathrm{im}$ idazolium chloride ( $\mathrm{pH} 6.6$ ), $0.01 \mathrm{M} \mathrm{MgCl}_{2}, 5 \mathrm{mM}$ dithiothreitol, $0.1 \mathrm{mM}$ spermidine, $0.5 \mathrm{mM} \mathrm{ADP}$, and $0.1 \mathrm{mM}$ EDTA. The mixture was incubated at $37^{\circ} \mathrm{C}$ for 30 minutes. The product was precipitated by adding 10 volumes of $2 \%$ $\mathrm{LiClO}_{4}$ in acetone, and further purified by electrophoresis in denaturing $20 \%$ polyacrylamide gel (PAGE). The oligonucleotide was electroeluted onto a DE-81 filter (Whatman, Brentford, UK), stripped from the filter with $3 \mathrm{M} \mathrm{LiClO}_{4}$ at $56^{\circ} \mathrm{C}$, and precipitated with $2 \% \mathrm{LiClO}_{4}$ in acetone. The precipitate was washed with acetone $(3 \times 200 \mu \mathrm{L})$, dried in vacuum, and dissolved in double-distilled water $(100 \mu \mathrm{L})$. The concentration of the resulting solution of the labeled oligonucleotide did not exceed $2.5 \times 10^{-7} \mathrm{M}$.

\section{Modification}

All modification was carried out in a buffer containing $0.16 \mathrm{M} \mathrm{NaCl}, 0.02 \mathrm{M}$ sodium phosphate ( $\mathrm{pH} 7.4$ ), and $1 \mathrm{mM}$ EDTA.

\section{Sensitized modification}

The absorption spectra of phthalocyanines contain the Soret band at about $340 \mathrm{~nm}$ and two Q-bands at $630 \mathrm{~nm}$ and $680 \mathrm{~nm}$ (Figures 3 and 4). Therefore, the reactive moiety of the conjugates can be excited at different wavelengths using light of a high-pressure mercury lamp $\left(\lambda_{\max }=365 \mathrm{~nm}\right)$ or a helium-neon laser $\left(\lambda_{\max }=633 \mathrm{~nm}\right)$, respectively.

Irradiation of the samples at $365 \mathrm{~nm}$ was carried out for 3 hours in a photochemical reactor equipped with a quartz rectangular cell of $0.1 \mathrm{~cm}$ path length. This cell was immersed

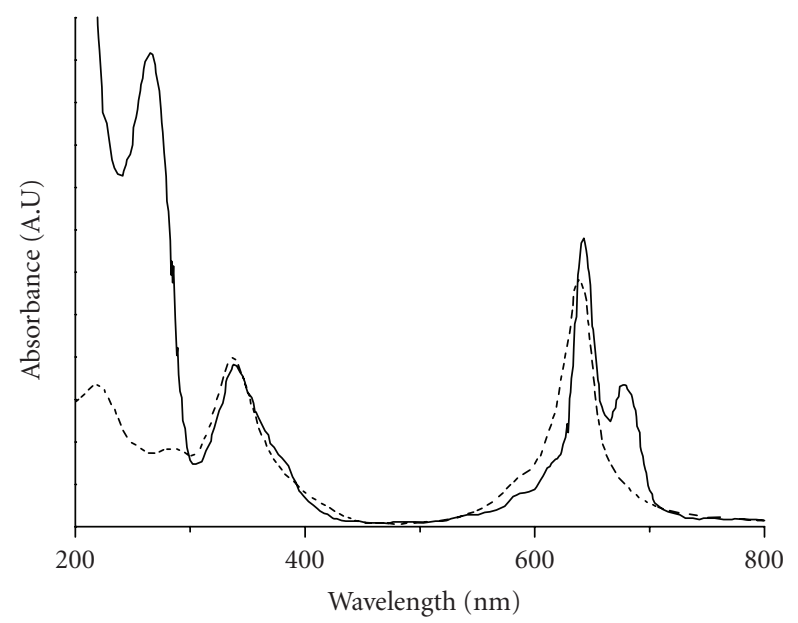

FIGURE 3: Absorption spectra of aqueous solutions of $\mathrm{Al}(\mathrm{III})$ tetra[4-carboxypentenylsulfamoyl]-phthalocyanine (dashed line) and its conjugate with $\mathrm{d}$ (pTCTTCCCA) (solid line).

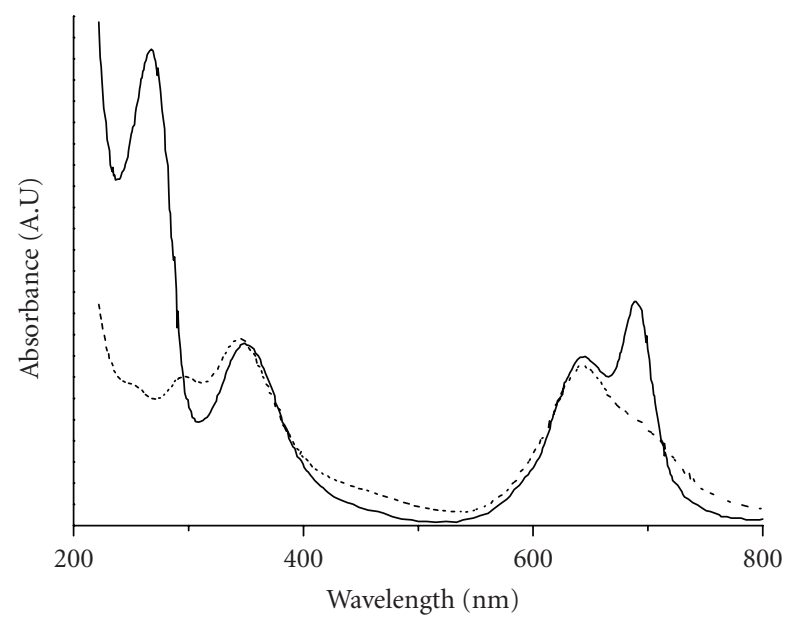

FIgURE 4: Absorption spectra of aqueous solution of $\mathrm{Zn}$ (II) tetra4-carboxymethylthiophtalocyanin (dashed line) and its conjugates with d(pTCTTCCCA) (solid line).

in a cuvette filled with the aqueous solution and placed in a thermostated holder at $5^{\circ} \mathrm{C}$. The light source was a 1000 W DRSh-1000 high-pressure mercury lamp (Electromash, Chelyabinsk, Russia). The intensity of the light entering the cuvette, $I_{0}$, was measured by ferrioxalate HatchardParker actinometry [14] and found to be $(1.43 \pm 0.07) \times$ $10^{16}$ photons $/\left(\mathrm{s} \times \mathrm{cm}^{2}\right)$. Selection of excitation wavelengths was performed by using a BS-4 glass filter (LZOS, Lytkarino, Russia) which cuts off the light of wavelength lower than $340 \mathrm{~nm}$. The high-pressure mercury lamp spectra consist of separate bands, and only one band $(\lambda=365)$ over $340 \mathrm{~nm}$ can excite reagents because of its overlap with the Soret band of phthalocyanines. The concentration of the target in the reaction mixtures was $1 \times 10^{-8} \mathrm{M}$, and the concentration of the 
conjugate $8.2 \times 10^{-5} \mathrm{M}$. Such concentrations were chosen in order to force all oligonucleotide targets into a duplex with the conjugate. Irradiation of the samples in the visible spectrum region was carried out for 30 minutes in $1.5 \mathrm{~mL}$ tubes (Eppendorf, Wesseling-Berzdorf, Germany) using a heliumneon laser $(633 \mathrm{~nm}, 10 \mathrm{~mW})$ at $25^{\circ} \mathrm{C}$. This wavelength corresponds to a Q-band of phthalocyanine absorption spectra.

The irradiated solutions were immediately transferred into polypropylene tubes containing $1 \mu \mathrm{L}$ of $1.4 \mathrm{mg} / \mathrm{ml}$ of total $E$ coli tRNA; $400 \mu \mathrm{L}$ of $2 \% \mathrm{LiClO}_{4}$ in acetone was then added. The precipitate was pelleted by centrifugation, washed twice with $80 \%$ ethanol and once with acetone, and dried in vacuum.

\section{Catalytic modification}

Oxidative modification of the 22-nt oligonucleotide with the complementary oligonucleotide carrying a $\mathrm{Co}$ (II)phthalocyanine moiety was performed at $25^{\circ} \mathrm{C}$ in two ways: (1) in the presence of $\mathrm{H}_{2} \mathrm{O}_{2}$ and (2) in the presence of $\mathrm{O}_{2}$ and 2 -mercaptoethanol as a reducing agent. The concentration of the target in the reaction mixtures was $10^{-8} \mathrm{M}$, the concentration of the conjugate was $8.22 \times 10^{-5} \mathrm{M}$, and the concentrations of $\mathrm{H}_{2} \mathrm{O}_{2}$ and 2-mercaptoethanol were $2.0 \times 10^{-4} \mathrm{M}$. The concentration of $\mathrm{O}_{2}$ in aqueous solutions at $25^{\circ} \mathrm{C}$ at atmospheric pressure is $2.0 \times 10^{-4} \mathrm{M}$. The sample volume was $10 \mu \mathrm{L}$; the incubation time was 24 hours.

\section{Identification and separation of modification products}

To cleave the modified oligonucleotide at the points of modification where it becomes labile to alkali treatment (apurinic/apyrimidinic sites and oxidized deoxyribose), the precipitates were dissolved in $50 \mu \mathrm{L}$ of $1 \mathrm{M}$ piperidine $(\mathrm{pH}$ 12) and incubated for 45 minutes at $95^{\circ} \mathrm{C}$ [15]. The products were precipitated and washed twice with $95 \%$ ethanol, once with acetone, and then dried in vacuum.

To digest the product oxidized at deoxyguanosine residues, including 8 -oxoguanine, which is relatively stable in alkali, the samples were treated with 8-oxoguanine-DNA glycosylase from E coli (Fpg protein). Prior to this treatment, the samples were washed twice with $85 \%$ ethanol and once with acetone to remove the buffer, and dried in vacuum. The precipitates were dissolved in $20 \mu \mathrm{L}$ of a buffer containing $50 \mathrm{mM}$ Tris- $\mathrm{HCl}$ ( $\mathrm{pH} 7.5), 50 \mathrm{mM} \mathrm{KCl}, 1 \mathrm{mM}$ EDTA, $1 \mathrm{mM}$ dithiothreitol, 9\% glycerol, and $6.6 \times 10^{-6} \mathrm{M}$ Fpg. After the reaction, the enzyme was twice extracted by the mixture of phenol-chloroform-isoamyl alcohol (25: $25: 1 \mathrm{v} / \mathrm{v} / \mathrm{v})$. The reaction mixtures were precipitated with 10 volumes of $2 \% \mathrm{LiClO}_{4}$ in acetone, centrifuged, washed twice with 95\% ethanol, dried, and dissolved in a marker dyes solution containing $0.1 \%$ bromophenol blue and $0.1 \%$ xylene cyanol FF.

The products of modification were separated by $20 \%$ PAGE in the presence of $7 \mathrm{M}$ urea. After electrophoresis, the gel was exposed to CP-BU X-ray film (Agfa-Gevaert, Mortsel, Belgium) for $10-20$ hours at $-10^{\circ} \mathrm{C}$.

\section{RESULTS}

The conjugates of deoxyribooligonucleotides with phthalocyanines of $\mathrm{Al}(\mathrm{III})$ and $\mathrm{Zn}$ (II) I-IV were studied as reagents for photochemical modification of nucleic acids (Figure 1). The oligonucleotides were connected to the phthalocyanine moieties through linkers with different numbers of $\mathrm{CH}_{2}$ groups: three in conjugates I and III and six in conjugates II and IV. Conjugate V containing $\mathrm{Co}(\mathrm{II})$-phthalocyanine was used as a reagent for catalytic modification in the presence of molecular oxygen (Figure 1). The linker in this conjugate consists of three $\mathrm{CH}_{2}$-groups. A 22-nt oligonucleotide served as the DNA target. The structure of the complementary duplexes formed between the DNA target and the conjugates is presented in Figure 2.

\section{UV/Visible spectra of free phthalocyanines and conjugates}

The conjugation of phthalocyanines with oligonucleotides was confirmed by the change in the spectrum shape at 600$700 \mathrm{~nm}$ in comparison with the absorption spectrum of free phthalocyanine. For free $\mathrm{Co}(\mathrm{II})$-phthalocyanine, an absorption band was observed at $678 \mathrm{~nm}$, with a shoulder around $630 \mathrm{~nm}$. In the case of the oligonucleotide conjugate $\mathrm{V}$, a band at $631 \mathrm{~nm}$ with a shoulder at $680 \mathrm{~nm}$ was detected [16]. For free $\mathrm{Al}(\mathrm{III})$-phthalocyanine, the only absorption band in the visible region was observed at $678 \mathrm{~nm}$; but for its oligonucleotide conjugates III and IV, two bands were found at $639 \mathrm{~nm}$ and $678 \mathrm{~nm}$ (see Figure 3). The spectrum of free $\mathrm{Zn}$ (II)-phthalocyanine contained a band at $643 \mathrm{~nm}$ with a shoulder at 680-700 nm (Figure 4). This band was broader than that for $\mathrm{Co}$ (II) and $\mathrm{Al}$ (III) complexes. The binding of $\mathrm{Zn}$ (II)-phthalocyanine with oligonucleotides I and II results in the appearance of a second band at $688 \mathrm{~nm}$. All conjugates demonstrate absorption near $260 \mathrm{~nm}$ most probably due to the contribution of the oligonucleotide part.

\section{Sensitized modification under $\mathrm{Hg}$ lamp irradiation $(\lambda=365 \mathbf{n m})$}

Modification of the 22-nt oligonucleotide was carried out at $5^{\circ} \mathrm{C}$. When the reaction products were analyzed by electrophoresis in 20\% PAAG, no direct cleavage of the target was observed. It is known that oxidation of DNA may lead to the appearance of alkali-labile sites [17]. These modifications are detected by the treatment of the reaction mixture with $1 \mathrm{M}$ piperidine ( $\mathrm{pH}$ 12) [15]. However, other modifications, which are stable in alkali, can also be found, for example, 8-oxoguanine. To detect this modification, the reaction mixtures were treated with Fpg protein, a repair enzyme from $E$ coli that cleaves DNA at guanine residues oxidized at $\mathrm{C} 8$, as well as at some others oxidized guanosine derivatives [18].

The reaction yields of target modification by $\mathrm{Zn}$ (II)phthalocyanine conjugates I and II containing aminopropanol and aminohexanol linkers were $18 \%$ and $14 \%$, respectively, as detected by piperidine treatment (Figure 5). The treatment with Fpg revealed only $8 \%$ and $6 \%$ 


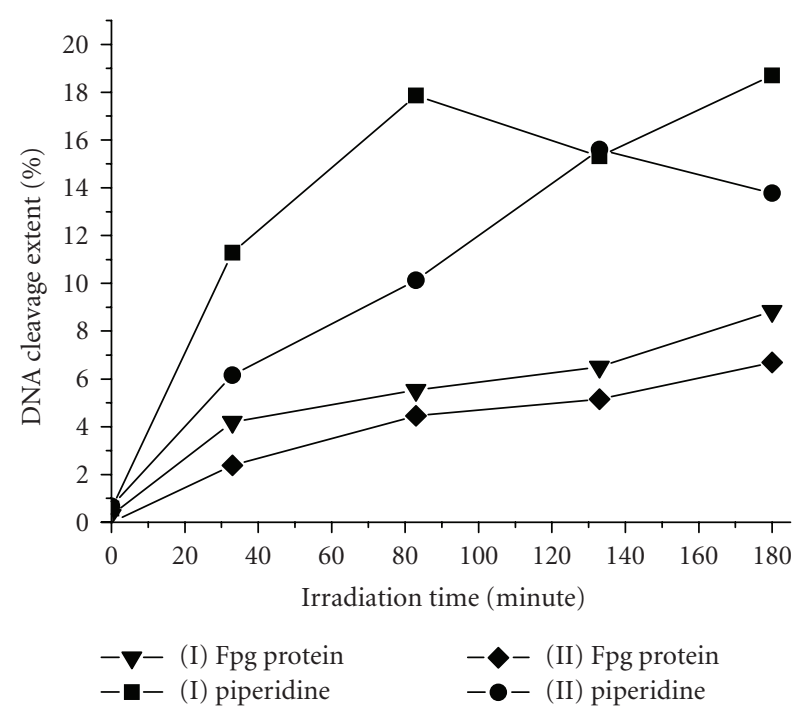

FIgURE 5: Time courses of photosensitized modification of the 22nt oligonucleotide target with $\mathrm{Zn}(\mathrm{II})$ phthalocyanine conjugates I $(\nabla, \boldsymbol{\square})$ and II $(\bullet, \bullet)$ after irradiation with an $\mathrm{Hg}$ lamp at $365 \mathrm{~nm}$. The postirradiation treatment was done using Fpg protein $(\boldsymbol{\nabla}, \boldsymbol{})$ and $1 \mathrm{M}$ piperidine $(\mathbf{\square}, \bullet)$.

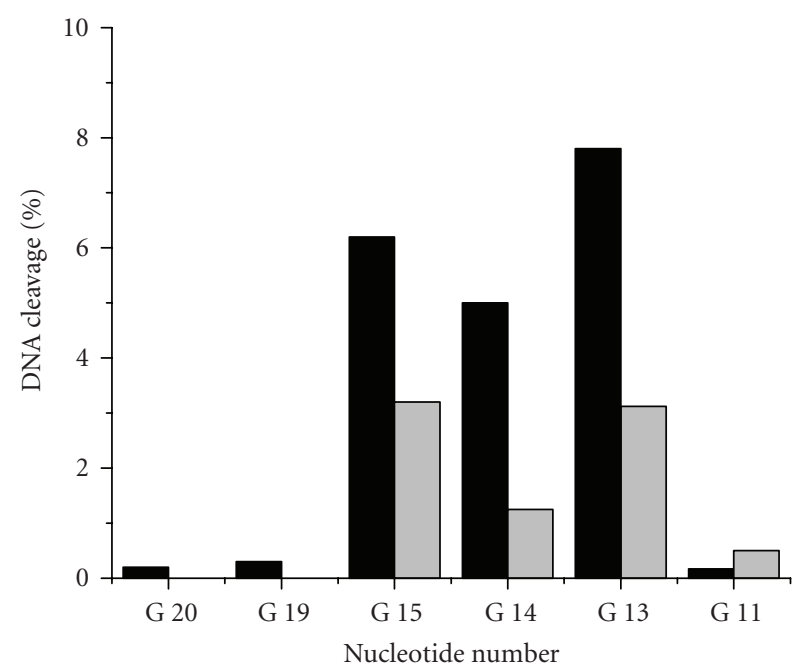

(I) piperidine

(I) Fpg protein

Figure 6: Distribution of base modifications in the 22-nt oligonucleotide target for sensitized modification with $\mathrm{Zn}(\mathrm{II})$-phthalocyanine conjugate I after irradiation by an $\mathrm{Hg}$ lamp at $365 \mathrm{~nm}$. The modifications were revealed by treatment with Fpg protein or $1 \mathrm{M}$ piperidine.

modification yield for conjugates I and II, respectively (Figure 5). A comparison of cleavage time courses demonstrates that the modification yield in the case of conjugate I is somewhat higher than for conjugate II. This may be

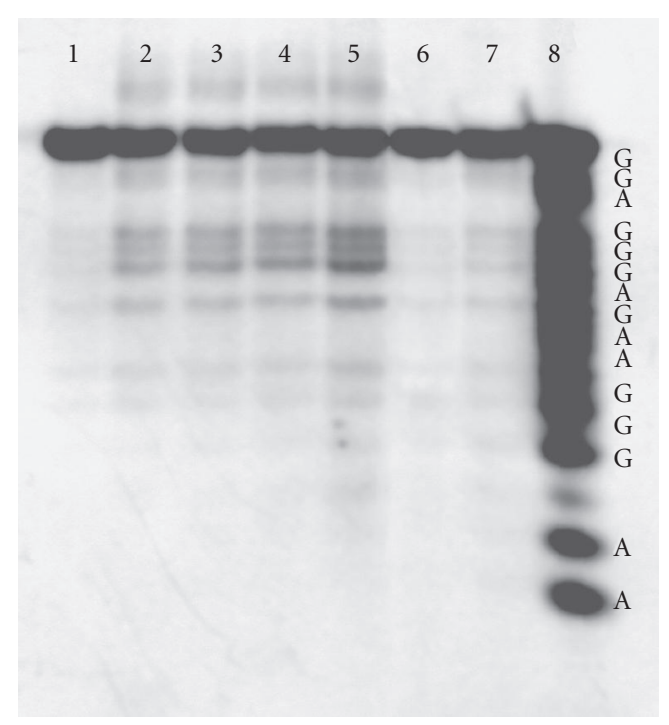

FIGURE 7: Autoradiogram of a $20 \%$ denaturing polyacrylamide gel showing a time course of cleavage of the 22-nt oligonucleotide target at $5^{\circ} \mathrm{C}$ by $\mathrm{Zn}(\mathrm{II})$-phthalocyanine conjugate $\mathrm{I}$ after irradiation by an $\mathrm{Hg}$ lamp at $365 \mathrm{~nm}$. Time points shown are 0 minutes (lane 1), 33.3 minutes (lane 2), 83.3 minutes (lane 3), 133.3 minutes (lane 4), and 180 minutes (lanes 5-7). The reaction mixture in lane 6 was not irradiated. The sample in lane 7 did not contain I. Lane 8 represents a Maxam-Gilbert $(A+G)$ sequencing reaction.

explained by an increase in the probability of consumption of the active oxygen species in by-processes in solution due to a longer spacer of conjugate II. The longer spacer of conjugate II moves the phthalocyanine moiety farther away from the oligonucleotide target as compared with conjugate I, resulting in an increased contribution of by-processes with the solvent.

The target modification by both $\mathrm{Zn}$ (II)-phthalocyanine conjugates I and II took place preferentially at guanine residues in the region $G^{11}-G^{20}$. Residues $G^{13}$ and $G^{15}$ were mainly modified, as can be seen from a histogram presented in Figure 6 for conjugate I. The autoradiogram of a gel corresponding to the time course of target modification by the conjugate I revealed by Fpg treatment is presented in Figure 7. The same data were obtained for conjugate II.

In the case of $\mathrm{Al}(\mathrm{III})$-phthalocyanine containing conjugate III (data are not shown), the modification yield approached $12 \%$ as detected by piperidine treatment, and was close to 5\% when Fpg protein was used to reveal modification points. The experiments with the $\mathrm{Al}$ (III)-containing conjugate IV resulted also in a rather low modification yield of $5-7 \%$ as revealed by both piperidine and Fpg protein treatments (data are not shown).

\section{Sensitized modification under helium-neon laser irradiation ( $\lambda=633 \mathbf{n m})$}

The reaction mixtures containing the phthalocyanine $\mathrm{Zn}$ (II) and $\mathrm{Al}(\mathrm{III})$ conjugates II and IV, respectively, were also 


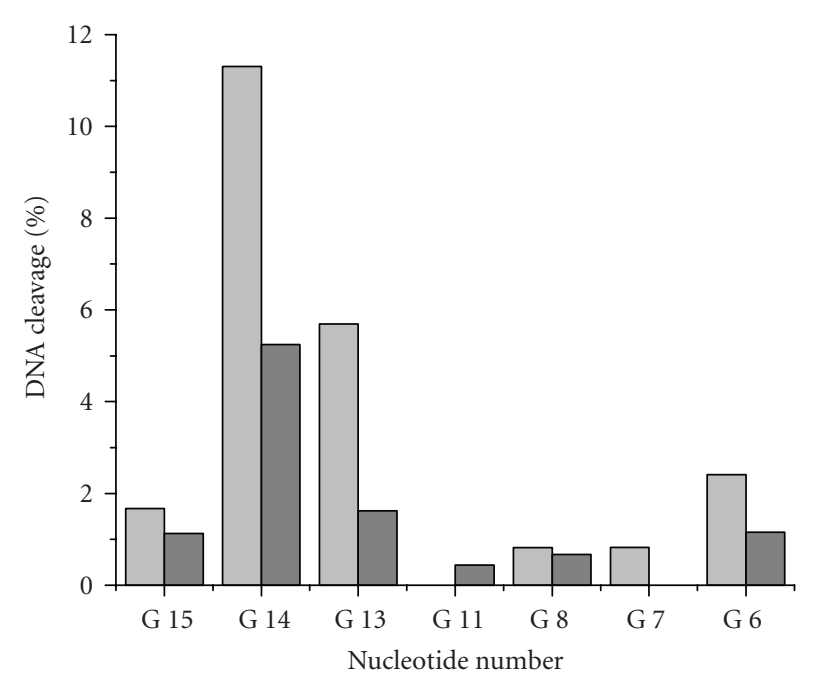

(II) piperidine

(IV) piperidine

FIGURE 8: Distribution of base modifications in the 22-nt oligonucleotide target for sensitized modification with the $\mathrm{Zn}(\mathrm{II})$ and $\mathrm{Al}(\mathrm{III})$ phthalocyanines conjugates II and IV after laser light irradiation at $633 \mathrm{~nm}$. The modifications were revealed by treatment with $1 \mathrm{M}$ piperidine.

irradiated by a helium-neon laser at a $633 \mathrm{~nm}$ wavelength for 30 minutes at $25^{\circ} \mathrm{C}$. In contrast to the experiments with an Hg lamp, no cleavage of oligonucleotide target in the absence of these reagents was observed because biopolymers do not absorb light in the red visible range of a spectrum. The laser light was much more intense than the Hg lamp light, as can be seen from a significant decrease in the required irradiation time. The experiments have demonstrated (Figure 8) that the modification yield detected by piperidine treatment was higher for $\mathrm{Zn}$ (II)-phthalocyanine as compared with $\mathrm{Al}(\mathrm{III})$-phthalocyanine and was $24 \%$ and $10 \%$, respectively.

Distribution of modification sites for the phthalocyanine $\mathrm{Al}(\mathrm{III})$ IV and $\mathrm{Zn}$ (II)-phthalocyanine II conjugates were quite similar (Figure 8). In addition to $\mathrm{G}^{13}-\mathrm{G}^{15}$, noticeable cleavage takes place at $\mathrm{G}^{6}, \mathrm{G}^{7}$, and $\mathrm{G}^{8}$ bands. A comparison with the data obtained with an $\mathrm{Hg}$ lamp irradiation at $5^{\circ} \mathrm{C}$ suggests that such difference may be due to the higher flexibility of the phthalocyanine moiety and the higher mobility of the oxidizing species at higher temperature.

\section{Catalytic modification}

The term "catalysis" used here applies to the mechanism of active oxygen species generation, where a metal-phthalocyanine moiety acts as a catalyst. The nucleic acid is oxidized by hydrogen peroxide, and metal-phthalocyanine catalyzes this process through reversible changes in its oxidation state.

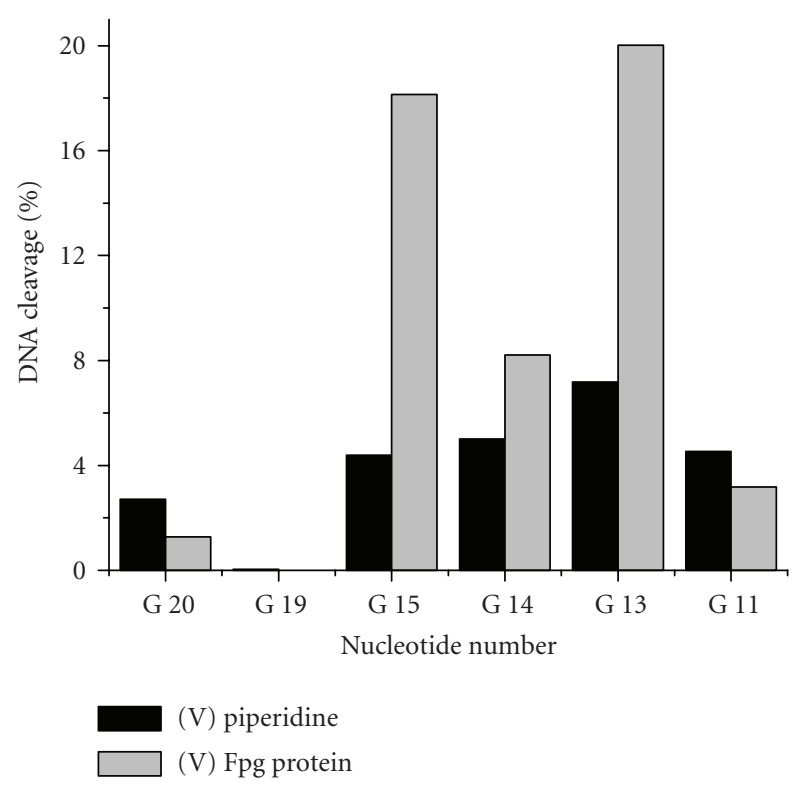

FIGURE 9: Distribution of base modifications in the 22-nt oligonucleotide target for catalytic oxidation by the $\mathrm{Co}(\mathrm{II})$-phthalocyanine conjugate $\mathbf{V}$ in the presence of $\mathrm{H}_{2} \mathrm{O}_{2}$, after the modifications were revealed by treatment with Fpg protein or $1 \mathrm{M}$ piperidine.

Modification of DNA in the complexes with the Co(II)phthalocyanine conjugate $\mathbf{V}$ were performed at $25^{\circ} \mathrm{C}$ with $\mathrm{H}_{2} \mathrm{O}_{2}$ and with $\mathrm{O}_{2}$ in the presence of 2-mercaptoethanol as a reducing compound. The PAGE separation of the reaction products has shown no direct cleavage of the target. Modifications were detected only after treatment of the reaction mixture either with $1 \mathrm{M}$ piperidine or with Fpg.

The modification yield in the presence of $\mathrm{O}_{2}$ and 2mercaptoethanol after $1 \mathrm{M}$ piperidine treatment was found to be $15 \%$, and in the presence of $\mathrm{H}_{2} \mathrm{O}_{2}$ it was approximately $35 \%$. The highest modification yield was achieved in approximately 20 hours. The modification yields determined by Fpg protein treatment were significantly higher, $70 \%$ for the reaction mixture containing hydrogen peroxide and approximately $25 \%$ for the reaction mixture containing $\mathrm{O}_{2}$ and 2mercaptoethanol.

The target modifications were localized mainly in the $\mathrm{G}^{13}-\mathrm{G}^{15}$ sequence, similar to the situation observed with the $\mathrm{Al}(\mathrm{III})$ - and $\mathrm{Zn}(\mathrm{II})$-phthalocyanine conjugates. The distribution of modifications was similar for the systems containing $\mathrm{O}_{2} / 2$-mercaptoethanol and hydrogen peroxide (Figure 9). However, the depth of modification in the case of hydrogen peroxide was notably higher. This is not unexpected for a replacement of the system " $\mathrm{O}_{2}+$ reducing reagent" with $\mathrm{H}_{2} \mathrm{O}_{2}$, which is a direct source of hydroxyl radicals. Detection of modification points by Fpg protein treatment reveals a higher modification yield than does piperidine treatment, most probably due to a preferential modification at the C8 position of guanine. 


\section{DISCUSSION}

In the present work, we show that tetracarboxyphthalocyanines of $\mathrm{Al}(\mathrm{III}), \mathrm{Zn}(\mathrm{II})$, and $\mathrm{Co}(\mathrm{II})$ modify nucleic acids when delivered to their DNA targets by means of a complementary oligonucleotide tag, and that the modification can be initiated either by irradiation or in the reactions of catalytic redox cycling. Our experiments indicate that no direct cleavage occurs in the model oligonucleotides. Phthalocyanines presumably incur damage on different moieties in DNA depending on whether photosensitization or redox catalysis takes place. Apurinic/apyrimidinic sites and deoxyribose oxidation were revealed under alkaline conditions, and oxidized nucleotide bases like 8-oxoguanosine, by treatment of the samples with Fpg protein. It was found that in the presence of the $\mathrm{Co}(\mathrm{II})$-phthalocyanine conjugate, the products of the catalytic modification in the DNA target are mainly substrates for Fpg protein but are poorly revealed by piperidine. When the high-pressure Hg lamp (365 nm wavelength) or laser irradiation $(633 \mathrm{~nm})$ were used, the sensitized modification products were better revealed by piperidine treatment than by Fpg protein. The relatively low levels of photomodification may be explained by the large migration distance $(\sim 90 \mathrm{~nm})$ of singlet molecular oxygen ${ }^{1} \mathrm{O}_{2}$ along the polynucleotide chain compared to the $0.34 \mathrm{~nm}$ distance between DNA bases [19] or formation of modified bases of different structure, not revealed by the detection methods used.

Nevertheless, our results unambiguously demonstrate that modification of nucleic acids occurs when the target and metallophthalocyanine group are drawn together. Similar results in sensitized photomodification of nucleic acids were obtained earlier with conjugates containing other reactive groups, including porphyrins and their analogs, such as $\mathrm{Pd}(\mathrm{II})$-coproporphyrin I [20], chlorine [21], sapphyrin, and Dy(III) texaphyrin [22]. Using oligonucleotide tags, it is possible to target the reagent to the required nucleic acid sequence, thus enhancing the selectivity of the process. Our results show that the generation of short-living oxygen species in the case of catalytic modification in the presence of the $\mathrm{Co}(\mathrm{II})$-phthalocyanine reagent results in sufficiently effective and sequence-specific modification of nucleic acids. The reactivity of these reagents towards DNA or RNA of foreign organisms or malignant tumor cells raises the possibility of blocking the expression of specific genes and using phthalocyanine conjugates as drugs.

\section{ACKNOWLEDGMENTS}

The authors are grateful to Dr Dmitri Pyshnyi for his help in the synthesis of oligonucleotides. This research was made possible in part by grants from RFBR (04-04-48171, 05-0448447, 06-04-49263), Presidium of the Russian Academy of Sciences (MCB Program, 10.5), the Russian Ministry of Education and Science (02.434.11.7064, NS-4526.2006.4), CRDF (Y1-B-08-16). Alexander A. Chernonosov is a recipient of the Lavrentyevs Fellowship from Siberian Division of the Russian Academy of Sciences. Vladimir V. Koval was supported by Postdoctoral fellowship from INTAS (04-83-3849).

\section{REFERENCES}

[1] Knorre DG, Vlassov VV, Zarytova VF, Lebedev AV, Fedorova OS. Design and Targeted Reactions of Oligonucleotide Derivatives. Boca Raton, Fla: CRC Press; 1994.

[2] Belikova AM, Zarytova VF, Grineva NI. Synthesis of ribonucleosides and diribonucleoside phosphates containing 2chloro-ethylamine and nitrogen mustard residues. Tetrahedron Letters. 1967;8(37):3557-3562.

[3] Uhlmann E, Peyman A. Antisense oligonucleotides: a new therapeutic principle. Chemical Reviews. 1990;90(4):543-584.

[4] Moser HE, Dervan PB. Sequence-specific cleavage of double helical DNA by triple helix formation. Science. 1987;238 (4827):645-650.

[5] Le Doan T, Perrouault L, Praseuth D, et al. Sequencespecific recognition, photocrosslinking and cleavage of the DNA double helix by an oligo-[alpha]-thymidylate covalently linked to an azidoproflavine derivative. Nucleic Acids Research. 1987;15(19):7749-7760.

[6] Fedorova OS, Knorre DG, Podust LM, Zarytova VF. Complementary addressed modification of double-stranded DNA within a ternary complex. FEBS Letters. 1988;228(2):273-276.

[7] Jori G. Far-red-absorbing photosensitizers: their use in the photodynamic therapy of tumours. Journal of Photochemistry and Photobiology A: Chemistry. 1992;62(3):371-378.

[8] Spikes JD. Phthalocyanines as photosensitizers in biological systems and for the photodynamic therapy of tumors. Photochemistry and Photobiology. 1986;43(6):691-699.

[9] Kochevar IE. Singlet oxygen signaling: from intimate to global. Science's STKE: Signal Transduction Knowledge Environment. 2004;2004(221):pe7.

[10] Halliwell B, Gutteridge JMC. Free Radicals in Biology and Medicine. 3rd ed. Oxford, UK: Oxford University Press; 1999.

[11] Vol'pin ME, Krainova NYu, Moskaleva IV, et al. Transitionmetal complexes as catalysts of active oxygen species formation in autooxidation reactions. 1. Cobalt and iron phthalocyanine complexes. Russian Chemical Bulletin. 1996;45(8): 2000-2007.

[12] Borer PN. Optical properties of nucleic acids, absorption and circular dichroism spectra. In: Fasman GD, ed. Handbook of Biochemistry and Molecular Biology: Nucleic Acids. Vol 1. 3rd ed. Cleveland, Ohio: CRC Press; 1975:589-595.

[13] Koval VV, Chernonosov AA, Abramova TV, et al. Photosensitized and catalytic oxidation of DNA by metallophthalocyanine-oligonucleotide conjugates. Nucleosides, Nucleotides \& Nucleic Acids. 2001;20(4-7):1259-1262.

[14] Hatchard CG, Parker CA. A new sensitive chemical actinometer. II. Potassium ferrioxalate as a standard chemical actinometer. Proceedings of the Royal Society of London. Series A, Mathematical and Physical Sciences. 1956;235(1203):518-536.

[15] Maxam AM, Gilbert W. Sequencing end-labeled DNA with base-specific chemical cleavages. Methods in Enzymology. 1980;65(1):499-560.

[16] Koval VV, Chernonosov AA, Abramova TV, Ivanova TM, Fedorova OS, Knorre DG. The synthesis of a cobalt(II) tetracarboxyphthalocyanine-deoxyribooligonucleotide conjugate as a reagent for the directed DNA modification. Russian Journal of Bioorganic Chemistry. 2000;26(2):104-110.

[17] Stubbe J, Kozarich JW. Mechanisms of bleomycin-induced DNA degradation. Chemical Reviews. 1987;87(5):1107-1136.

[18] Henderson PT, Jones D, Hampikian G, Kan Y, Schuster GB. Long-distance charge transport in duplex DNA: the phononassisted polaron-like hopping mechanism. Proceedings of the 
National Academy of Sciences of the United States of America. 1999;96(15):8353-8358.

[19] Lehninger AL, Nelson DL, Cox MM. Principles of Biochemistry. 2nd ed. New York, NY: Worth; 1993.

[20] Fedorova OS, Savitskii AP, Shoikhet KG, Ponomarev GV. Palladium(II)-coproporphyrin I as a photoactivable group in sequence-specific modification of nucleic acids by oligonucleotide derivatives. FEBS Letters. 1990;259(2):335-337.

[21] Boutorine AS, Brault D, Takasugi M, Delgado O, Hélène C. Chlorin-oligonucleotide conjugates: synthesis, properties, and red light-induced photochemical sequence-specific DNA cleavage in duplexes and triplexes. Journal of the American Chemical Society. 1996;118(40):9469-9476.

[22] Magda D, Wright M, Miller RA, Sessler JL, Sansom PI. Sequence-specific photocleavage of DNA by an expanded porphyrin with irradiation above $700 \mathrm{~nm}$. Journal of the American Chemical Society. 1995;117(12):3629-3630. 


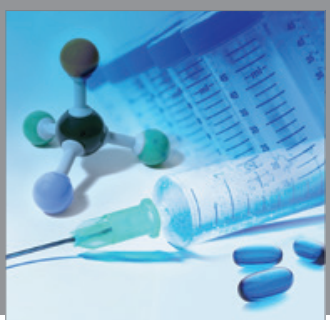

International Journal of

Medicinal Chemistry

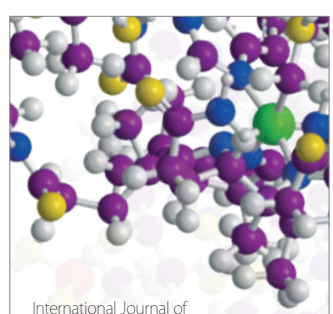

Carbohydrate Chemistry

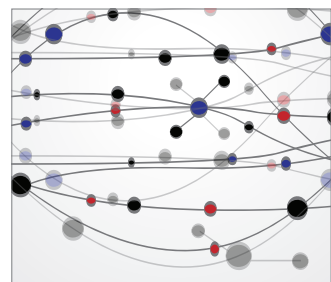

The Scientific World Journal
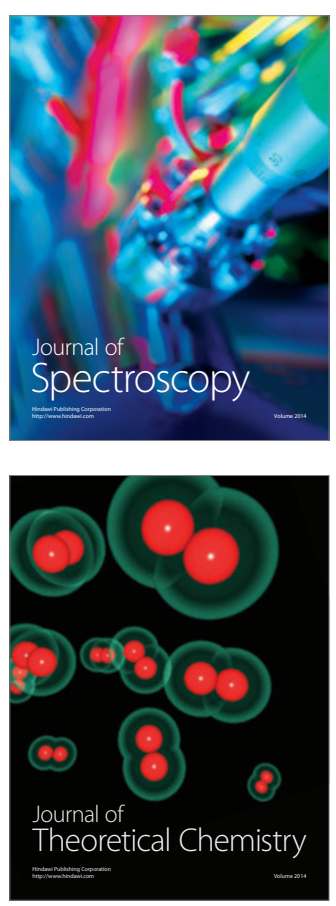
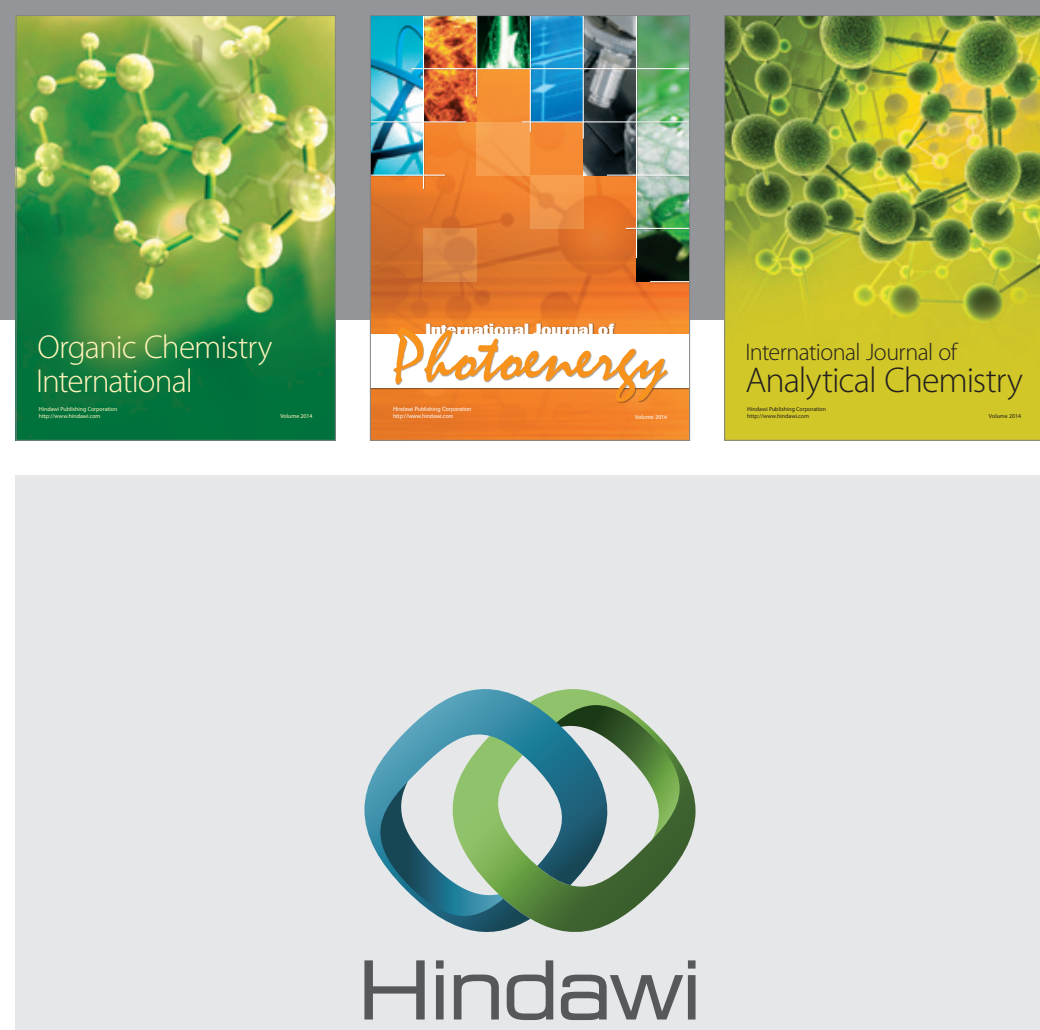

Submit your manuscripts at

http://www.hindawi.com
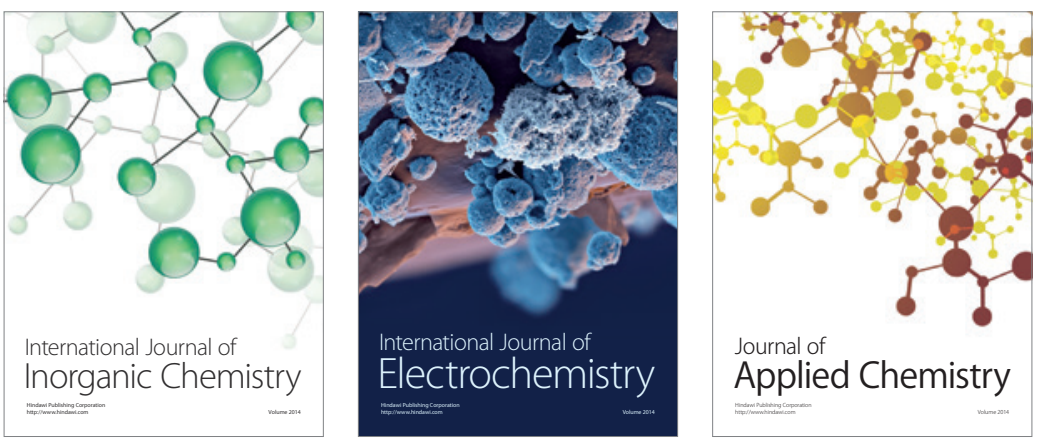

Journal of

Applied Chemistry
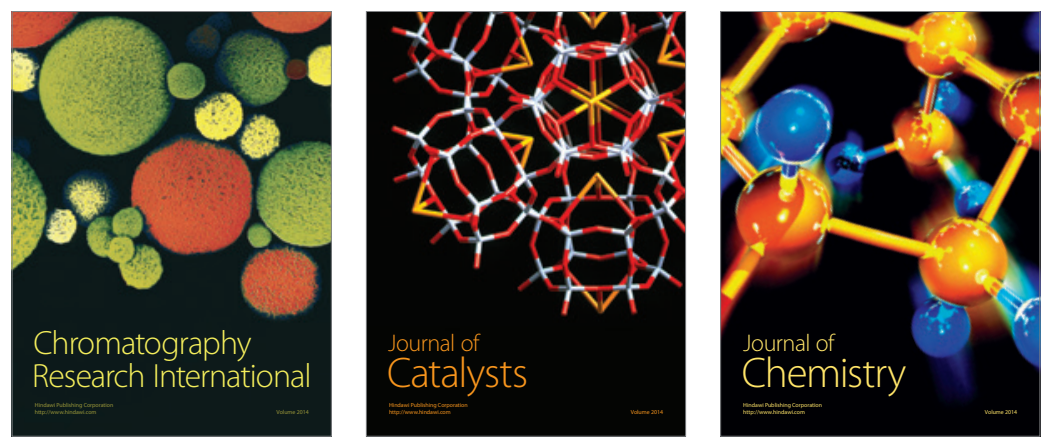
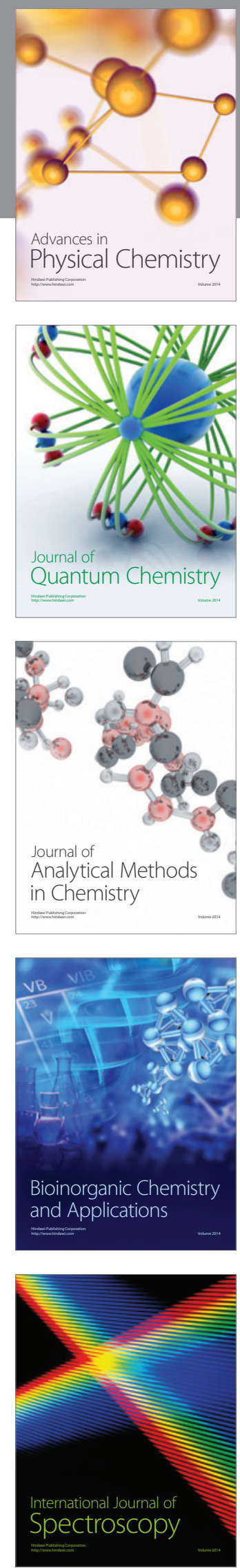